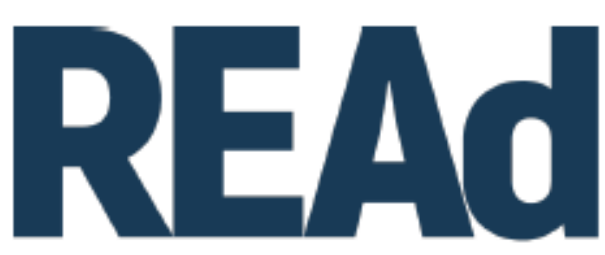

Revista Eletrônica de Administração

\title{
INFLUÊNCIA DOS OBJETIVOS COLABORATIVOS NA MENSURAÇÃO DO DESEMPENHO DA COOPERAÇÃO MEDIADA PELAS CARACTERÍSTICAS DE TRANSAÇÃOO ${ }^{1}$
}

Mara $\operatorname{Vogt}^{2}$

Ilse Maria Beuren ${ }^{3}$

Marcia Zanievicz da Silva ${ }^{4}$

\section{http://dx.doi.org/10.1590/1413-2311.302.98058}

\section{RESUMO}

Este estudo analisa a influência dos objetivos colaborativos nas práticas da mensuração do desempenho da cooperação, mediada pelas características de transação do setor de compras de hospitais. Uma survey foi realizada com 1.224 indivíduos da área de compras de hospitais do Brasil identificados no LinkedIn, desses 529 aceitaram o convite para participar da rede, aos quais se enviou o link do questionário, e a amostra final consiste das 120 respostas válidas. Para análise dos dados foi aplicada a modelagem de equações estruturais. Os resultados indicam que os objetivos colaborativos influenciam positivamente as características de transação entre comprador-fornecedor, assim como a mensuração do desempenho da cooperação. Porém, não foi observada mediação das características de transação entre comprador-fornecedor na relação dos objetivos colaborativos com a mensuração do desempenho. Conclui-se que quanto mais objetivos colaborativos houver no setor de compras de hospitais, menos arriscadas serão as características de transação relativas à variabilidade ambiental e interdependência de tarefas e, quanto maiores forem os objetivos colaborativos, melhor será o desempenho da cooperação

\footnotetext{
${ }^{1}$ Recebido em 8/11/2019, aceito em 20/10/2020.

${ }^{2}$ Universidade Regional de Blumenau - Programa de Pós-Graduação em Ciências Contábeis; Blumenau - SC (Brasil); http://orcid.org/0000-0002-3951-4637; maravogtcco@ gmail.com.

${ }^{3}$ Universidade Federal de Santa Catarina - Programa de Pós-Graduação em Contabilidade; Florianópolis - SC (Brasil); http://orcid.org/0000-0003-4007-6408; ilse.beuren@gmail.com.

${ }^{4}$ Universidade Regional de Blumenau - Programa de Pós-Graduação em Ciências Contábeis; Blumenau - SC (Brasil); http://orcid.org/0000-0003-1229-7705; mzsilva@ furb.br.
} 
comprador-fornecedor. O estudo contribui ao ressaltar a influência dos objetivos colaborativos no setor de compras de hospitais, tendo em vista a variabilidade ambiental e interdependência de tarefas, assim como o desempenho operacional, dos funcionários e de inovação.

Palavras-chave: Objetivos Colaborativos. Mensuração do Desempenho. Características de Transação. Setor de Compras de Hospitais.

\section{INFLUENCE OF COLLABORATIVE GOALS ON COOPERATION PERFORMANCE MEASUREMENT MEDIATED BY TRANSACTION CHARACTERISTICS}

This study analyzes the influence of collaborative objectives on cooperation performance measurement practices, mediated by the transaction characteristics of the hospitals' purchasing sector. A survey was carried out with 1,224 individuals from the procurement area of hospitals in Brazil identified on LinkedIn, of those 529 accepted the invitation to participate in the network, to whom the questionnaire link was sent, and the final sample consists of 120 valid responses. For data analysis, structural equation modeling was applied. The results indicate that collaborative objectives positively influence buyer-supplier transaction characteristics, as well as the measurement of cooperation performance. However, there was no mediation of transaction characteristics between buyer-supplier in the relationship of collaborative objectives with the performance measurement. It is concluded that the more collaborative objectives there are in the hospital purchasing sector, less risky will be the transaction characteristics related to environmental variability and task interdependence, and the higher the collaborative objectives, the greater the performance of the buyer-supplier cooperation. The study contributes by highlighting the influence of collaborative objectives in the hospital purchasing sector, in view of environmental variability and task interdependence, as well as operational, employee and innovation performance.

Keywords: Collaborative Objectives. Performance Measurement. Transaction Features. Hospital Purchasing Sector.

\section{INFLUENCIA DE LOS OBJETIVOS COLABORATIVOS EN LA MEDICIÓN DEL DESEMPEÑO DE LA COOPERACIÓN MEDIADO POR LAS CARACTERÍSTICAS DE LA TRANSACCIÓN}

Este estudio analiza la influencia de los objetivos de colaboración en las prácticas de medición (c) $(1)($ $)$ REAd | Porto Alegre - Vol. 26 - N.o 3 - Setembro / Dezembro 2020 - p. 765-795. 
del desempeño de la cooperación, mediada por las características de transacción del sector de compras de los hospitales. Se realizó una encuesta con 1.224 personas del área de compras de hospitales de Brasil identificadas en LinkedIn, de esas 529 aceptaron la invitación para participar en la red, a quienes se les envió el link del cuestionario, y la muestra consta de 120 respuestas válidas. Para el análisis de dados se aplicó el modelado de ecuaciones estructurales. Los resultados indican que los objetivos de colaboración influyen positivamente en las características de transacción comprador-proveedor, así como en la medición del desempeño de la cooperación. Sin embargo, no hubo mediación de las características de transacción entre comprador-proveedor en la relación de objetivos de colaboración con la medición del desempeño. Se concluye que cuanto más objetivos de colaboración haya en el sector de compras de hospitales, menos riesgosas serán las características de la transacción relacionadas con la variabilidad ambiental y la interdependencia de las tareas, y cuanto mayor sean los objetivos de colaboración, mayor será el desempeño de la cooperación comprador-proveedor. El estudio contribuye al destacar la influencia de los objetivos de colaboración en el sector de compras de hospitales, en vista de la variabilidad ambiental y la interdependencia de tareas, así como el desempeño operativo, de los empleados y la innovación.

Palabras clave: Objetivos de Colaboración. Medición del Desempeño. Características de la Transacción. Sector de Compras de Hospitales.

\section{INTRODUÇÃO}

Dyer e Singh (1998) já elucidavam que organizações que conseguem acumular recursos valiosos, não substituíveis, raros e difíceis de imitar, por meio de redes colaborativas, tendem a alcançar maior vantagem competitiva do que as demais. Os relacionamentos interorganizacionais podem ser fontes de valor para as redes, dado a aproximação do relacionamento e as escolhas estratégicas, que ajudam a alavancar e/ou manter a vantagem competitiva (MACEDO et al., 2017). Tais redes colaborativas referem-se à parceria entre clientes e fornecedores (DEKKER et al., 2019). Lai, Tam e Chan (2012) explicam que estas redes representam entidades que apoiam o esforço compartilhado, com vistas em oferecer benefícios coletivos, seja de produtos ou serviços.

As redes colaborativas são essenciais e facilitadoras dos avanços na tecnologia de informação e comunicação (ABREU; MACEDO; CAMRINHA-MATOS, 2009). No entanto, Schreiner, Kale e Corsten (2009) advertem que, por mais que as redes colaborativas tragam benefícios, há riscos nesse relacionamento, o que exige atenção e gerenciamento constante, para 
que as organizações consigam atingir os objetivos pretendidos na colaboração. Neste aspecto, Dekker, Ding e Groot (2016) aduzem que as características da transação são determinadas pela importância estratégica da colaboração e, por sua vez, influenciam as práticas de gerenciamento de desempenho das empresas envolvidas.

A Teoria dos Custos de Transação visa explicar as decisões relacionadas ao limite organizacional de fazer, comprar ou aliar e, assim como a maioria das teorias influentes, a mesma continua a ser refinada e reformulada, corrigida e expandida (GEYSKENS; STEENKAMP; KUMAR, 2006). De acordo com essa teoria, os custos envolvidos nas transações são denominados de custos de transação (TEO; YU, 2005). Dessa forma, depreendese que os riscos que advêm de um relacionamento interorganizacional estão implicados nos preceitos da Teoria dos Custos de Transação.

O aumento dos riscos de transação leva ao maior uso inter-relacionado do compartilhamento de informações, da configuração de metas, das revisões operacionais, do suporte ao fornecedor e da resolução de objetivos conjuntos (DEKKER; SAKAGUCHI; KAWAI, 2013). Assim é primordial que se compreenda a forma como os gestores usam controles durante as transações, com a finalidade de complementar contratos incompletos (ANDERSON; DEKKER, 2014). Nesse sentido, observa-se um aumento do número de pesquisas na área da Contabilidade Gerencial que têm centrando maior atenção nas últimas décadas sobre a forma como os contratos fornecem uma visão relativa ao controle gerencial das relações interfirmas (DEKKER; VAN DEN ABBEELE, 2010; ANDERSON; DEKKER, 2014; DEKKER, 2016; DEKKER et al. 2019).

É notável que pesquisadores da área contábil vêm demonstrando interesse crescente nas práticas de gerenciamento e controle de relações interorganizacionais (DEKKER, 2016). Contudo, a maioria dessas pesquisas foca nas relações intrafirmas e, portanto, são limitadas em tal contexto. Por outro lado, os estudos interfirmas se concentram principalmente nas questões relacionadas ao gerenciamento da colaboração com parceiros e seu comportamento, o que dificulta o acesso a tais informações e, consequentemente, desafia a realização de pesquisas (DEKKER, 2016). Por mais que as relações interfirmas sejam consideradas um campo de difícil e delicado acesso, pesquisas teórico-empíricas são necessárias para compreender suas nuances.

Organizações que empregam a colaboração interfirmas em suas transações vislumbram melhorar seu desempenho e maximizar suas vantagens competitivas, o que é fundamental em ambientes altamente dinâmicos e turbulentos (FYALL; GARROD; WANG, 2012). A colaboração a partir de redes ocorre de diversas formas e, em uma variedade de entidades, largamente autônomas, geograficamente distribuídas e heterogêneas no que diz respeito ao 
ambiente operacional, a cultura, ao capital social e às metas, mas que buscam alcançar objetivos comuns ou que sejam compatíveis na resolução de problemas, produção ou inovação (PICARD; RABELO, 2010).

Os objetivos colaborativos podem ser um diferencial na realização de transações interfirmas. De acordo com Provan e Mikward (2001), na área de cuidados com a saúde as relações interorganizacionais são consideradas um mecanismo eficaz na prestação de serviços. Segundo Provan, Fish e Sydow (2007), isso decorre principalmente do aumento de subespecializações na área e sua natureza fragmentada. Ainda em relação ao contexto supracitado, Wald et al. (2018) aduz que as redes colaborativas na área hospitalar vão além das expectativas, com evidências de uma rápida difusão da prática e implementação bem-sucedida.

Redes colaborativas em hospitais são importantes por se tratar de organizações complexas (PIZZINI, 2006; LEHTONEN, 2007; SOUZA et al., 2009), o que aumenta a demanda por informações mais acuradas para a tomada de decisão (SOUZA et al., 2009). Além disso, é um campo em que há dualidade no processo gerencial, percebida entre diferentes áreas (ex.: assistencial e administrativa), geralmente orientadas por vetores que se colocam em posições antagônicas (VENDEMIATTI et al., 2010). Portanto, avaliações do desempenho da cooperação são essenciais a fim de mensurar a eficiência, além das preocupações com a responsabilidade de setores como o de compras no que diz respeito às patentes, prazos de validade, dentre outras questões (SOUZA et al., 2009).

Nesta perspectiva, argumenta-se que as práticas da mensuração do desempenho podem ser influenciadas pelos objetivos colaborativos, devido à complexidade inerente e demandas de informações sobre o desempenho da cooperação. Da mesma forma, o desempenho dessas organizações pode ser influenciado pelas características de transação. De acordo com Dekker, Ding e Groot (2016), as características de transação medeiam os efeitos da importância estratégica da colaboração no uso de práticas de gerenciamento de desempenho e são determinadas pelos objetivos das empresas, o que influencia suas práticas.

Nota-se uma carência de estudos neste contexto, o que indica uma lacuna de pesquisa a ser investigada. Dekker, Ding e Groot (2016) enfatizam a necessidade de se analisar de que forma o alinhamento entre os objetivos colaborativos e as características de transação afetam o desempenho das relações de interação. Combs e Ketchen (1999) já salientavam que é preciso esforço maior por parte dos pesquisadores, com vistas em compreender como essas forças se combinam para influenciar a ação e o desempenho organizacional.

Com base no exposto e principalmente nos insights do estudo de Dekker, Ding e Groot (2016), tem-se a seguinte questão de pesquisa: Qual a influência dos objetivos colaborativos 
entre comprador-fornecedor nas práticas da mensuração do desempenho da cooperação, mediada pelas características de transação? Assim, este estudo objetiva analisar a influência dos objetivos colaborativos nas práticas da mensuração do desempenho da cooperação, mediada pelas características de transação do setor de compras de hospitais.

Este estudo diferencia-se do realizado por Dekker, Ding e Groot (2016), ao não considerar o compartilhamento de informações e a interação dos expansores de fronteira (boundary spanner interaction). Também por ser realizado em outro contexto (brasileiro), outra população (hospitais) e outro setor (compras), o que possibilita um avanço e contribuição teórica e prática. O estudo oferece contribuição teórica ao considerar um campo diferente do que já foi investigado, suprindo uma lacuna teórica relacionada ao setor de compras de hospitais, em especial ao buscar evidências sobre a influência dos objetivos colaborativos nas práticas da mensuração do desempenho da cooperação, mediada pelas características de transação do setor de compras de organizações hospitalares.

A contribuição prática do estudo é observada na medida em que os resultados da pesquisa proporcionam aos hospitais, em particular ao seu setor de compras, uma melhor compreensão de como os objetivos colaborativos e as redes de relacionamentos colaborativos podem auxiliar na competitividade e refletir no desempenho da cooperação, a partir das suas características de transação. Além disso, fomenta uma reflexão de que se a relação compradorfornecedor não for gerenciada de forma adequada, poderá acarretar consequências negativas para todos os envolvidos na relação de cooperação.

Portanto, a relevância do estudo está em investigar relações interfirmas no departamento de compras de hospitais, um campo em que a literatura aponta lacunas de pesquisa. Nesse contexto, os objetivos colaborativos são relevantes, por envolverem riscos consideráveis relacionados à cooperação, e se não gerenciados e controlados adequadamente, podem refletir em desempenho indesejado, além de falhas (LUNNAN; HAUGLAND, 2008; DEKKER; DING; GROOT, 2016; DEKKER et al., 2019). Por outro lado, a colaboração interfirmas pode trazer uma série de benefícios, como melhor posição no mercado, acesso mais fácil a recursos e aprendizagem organizacional (DAS; TENG, 1996; KALE; SINGH, 2007), imprescindíveis no contexto organizacional.

\section{REFERENCIAL TEÓRICO}

\subsection{Objetivos colaborativos e características de transação}

A colaboração interfirmas pode ocorrer por meio de uma variedade de acordos cooperativos. Das e Teng (1996) apontam algumas dessas formas: relações com fornecedores, 
joint ventures, troca de tecnologia, pesquisa e desenvolvimento, dentre outros. A colaboração interfirmas é associada a amplos benefícios. Dyer e Singh (1998) salientam que, para diversas empresas, essa colaboração é a chave da vantagem competitiva, devido a possibilidade de criação de valor ao combinar recursos e compartilhar conhecimentos e competências.

Nas estratégias interfirmas faz-se necessária uma análise diferenciada, pois se não fosse o relacionamento, a criação de valor e a busca pela realização dos objetivos, a empresa seguiria um caminho bem distinto (ZAJAC; OLSEN, 1993). Hagedoorn (1993) destaca que, embora em acordos com parceiros relacionados ao compartilhamento de objetivos haja menor controle por parte da administração e menor supervisão, diversas organizações deixaram de resistir e parecem preferir a cooperação para aumentar suas vantagens competitivas.

Groot e Merchant (2000) alertam que os objetivos colaborativos afetam na escolha de sistemas, um dos mecanismos de controle, e que, se os objetivos não são formulados tendo em vista retornos financeiros, maior tende a ser a confiança nos resultados. Os autores apresentam quatro categorias principais de objetivos: (1) reduzir custos; (2) obter acesso ao mercado; (3) obter acesso a desenvolvimentos ou conhecimentos tecnológicos e; (4) reduzir riscos. Glaister e Buckley (1996) apresentaram uma lista com cinco objetivos colaborativos: (1) desenvolvimento e transferência de tecnologia; (2) entrada em novos mercados; (3) manutenção da posição atual do mercado; (4) melhor utilização dos recursos; e, (5) redução dos riscos. Notam-se semelhanças nos objetivos de ambos os estudos, o que sugere que são objetivos relevantes para as organizações considerarem a colaboração entre si.

Um aspecto relevante relacionado aos objetivos colaborativos é que cada empresa deve ter acesso ao know-how da outra, e poder usar este conhecimento a favor de todos (KHANNA; GULATI; NOHRIA, 1998). Sob essa perspectiva, Madhok (2002) destaca que a colaboração pode permitir a transferência de habilidades e conhecimentos, o que aumenta a competitividade, que é o objetivo dessa colaboração. Madhok (2002) menciona que a colaboração interfirmas também permite que as empresas tenham acesso a recursos que não seriam possíveis de outra forma, ou custosos, de difícil acesso, demorados para conseguir.

Reuer e Arino (2007) aduzem que, a partir dos objetivos colaborativos, as empresas muitas vezes atingem objetivos múltiplos de forma simultânea. Decorre que, inicialmente, as empresas se preocupam com os objetivos próprios e, com essa colaboração, tendem a dar importância aos objetivos de ambas as partes. Os objetivos colaborativos visam ao compartilhamento de informações, que podem envolver questões estratégicas, questões relacionadas aos indivíduos, resolução de problemas que refletem no coletivo, além de forçar e fortalecer cada vez mais esse compartilhamento de conhecimentos (WANG et al., 2014). 
Quanto maior a importância estratégica da colaboração para a empresa, maior será a vontade de investir, o que envolve características de transação (especificidade dos ativos, interdependências das tarefas e variabilidade ambiental). Tais características são uma função dos objetivos colaborativos (DEKKER; DING; GROOT, 2016). As transações das empresas geralmente são precedidas de negociações entre os parceiros, por acreditarem que isso trará benefícios para ambos, uma alternativa que vai além dos mercados ou hierarquias (ANDERSON; DEKKER, 2014). Neste sentido, Dekker, Ding e Groot (2016) investigaram, para além das características de transação, como os determinantes exógenos das escolhas de controle (objetivos colaborativos das empresas) se associam com a natureza da transação, além dos controles adotados para realizar tais objetivos colaborativos.

Para Dekker e Van den Abbeele (2010) na medida em que os riscos de transação aumentam, de acordo com as características de transação, as empresas que possuem parcerias interfirmas usam mais indicadores para mensurar o desempenho, a fim de aumentar o controle e, como os objetivos são colaborativos, utilizar mais indicadores de desempenho, para além dos tradicionais, de modo a obter maior acurácia na mensuração do desempenho. Madhok (2002) argumenta que, o fato de existirem variações na forma organizacional com características de transação semelhantes ou, o fato de empresas tratarem transações similares de maneiras diferentes, demonstra que as relações interfirmas são diferentes e devem ser analisadas detalhadamente. Segundo Zajac e Olsen (1993) a estrutura de valor transacional em relações interorganizacionais é abstrata e exige maior desenvolvimento.

Neste aspecto tem-se que as decisões sobre a especificidade dos ativos referem-se aos investimentos realizados em ativos humanos ou físicos que têm pouco ou nenhum valor fora da transação, por isso exigem coordenação dentro destes limites (DEKKER; SAKAGUCHI; KAWAI, 2013). Por sua vez, as decisões que se referem às tarefas interdependentes implicam que os resultados e ações de determinado parceiro da relação interfirmas estejam condicionados aos resultados e ações do outro (OXLEY; SAMPSON, 2004; ANDERSON; DEKKER, 2005). Já a variabilidade ambiental diz respeito às atividades do fornecedor, requisitos do cliente, ações dos concorrentes, desenvolvimentos tecnológicos e de produtos/serviços, dentre outros (DEKKER; SAKAGUCHI; KAWAI, 2013).

Correia (2001) investigou a possibilidade de utilização do conceito de custos de transação na avaliação e seleção dos fornecedores e considerou o papel estratégico de compras na empresa e a tomada de decisão. Para tanto, três empresas farmacêuticas típicas do Brasil foram selecionadas para o estudo, sendo uma delas um laboratório governamental, outra um laboratório multinacional e outra um laboratório nacional. Quando o autor analisou as 
características de transação, verificou que o relacionamento colaborativo compradorfornecedor, no longo prazo, assegura a estratégia de produção. Além disso, essas estratégias de compras devem estar alinhadas com a estratégia competitiva da empresa. Assim, com base no exposto, formulou-se a primeira hipótese de pesquisa:

$\mathrm{H}_{1}$ : Os objetivos colaborativos entre comprador-fornecedor influenciam positivamente nas características de transação.

Espera-se que, quando aumenta o número de objetivos colaborativos, ou seja, quando a organização busca alcançar objetivos múltiplos com a colaboração, também aumentem as características de transação, essas representadas conforme Dekker, Ding e Groot (2016) pela especificidade dos ativos (o que facilita o seu fornecimento), pela maior interdependência das tarefas e pela variabilidade ambiental (para que haja pouca variabilidade ambiental).

\subsection{Mensuração do desempenho como prática de gerenciamento nas relações interfirmas}

A mensuração do desempenho da cooperação é um importante mecanismo para acompanhar os resultados e avaliar o relacionamento interfirmas na consecução dos objetivos individuais e coletivos (LANGFIELD-SMITH; SMITH, 2003; DEKKER; VAN DEN ABBEELE, 2010; SCHLOETZER, 2012). Facilita a comunicação e a resolução de problemas que advêm das relações interfirmas (DEKKER, 2004) e permite que as empresas com relações colaborativas partilhem e interajam com suas parceiras, tendo em vista seus objetivos colaborativos, e forneçam informações críticas e relevantes (MAHAMA, 2006; DEKKER; SAKAGUCHI; KAWAI, 2013; REUER; KLIJN; LIOUKAS, 2014).

Ittner, Larcker e Randall (2003) apontam duas abordagens gerais de medidas de desempenho: (i) abordagem simples, que exige que as empresas mensurem e usem um conjunto diversificado de medidas financeiras e não financeiras; e (ii) abordagem baseada no valor econômico e na criação de valor, na qual argumentam que a mensuração do desempenho deve ser alinhada com o objetivo final da organização. Focalizados na cooperação interfirmas, Langfield-Smith e Smith (2003) sustentam que os gestores devem medir e monitorar todas as operações e comportamentos a partir da mensuração do desempenho interfirmas, realizando o benchmarking, além de utilizar medidas de desempenho, como satisfação do cliente, capacidade de resposta, qualidade do produto, custo do produto.

Nesta mesma perspectiva, Mahama (2006) ressalta que é importante utilizar informações relacionadas ao desempenho da cooperação, quando se considera os objetivos colaborativos. Tais objetivos auxiliam na tomada de decisões corretivas, na redução de incertezas, na promoção da aprendizagem organizacional, entre outros. Da mesma forma, Wang 
et al. (2014) afirmam que as empresas tendem a utilizar os objetivos colaborativos e a integração para superar os limites organizacionais, o que implica em incertezas, mas tende a melhorar o desempenho coletivo dos participantes da cooperação.

De acordo com Wang et al. (2014), a colaboração interfirmas concentra-se em processos de tomada de decisão que incluem compartilhamento de informações e conhecimento, envolvem atividades humanas para perseguir os objetivos estratégicos compartilhados e atingir a resolução conjunta de problemas. Sendo assim, essa colaboração interfirmas contribui para o que Wang et al. (2014) denominaram de estratégias de ganha-ganha, ou seja, o valor da colaboração entre os parceiros. Ademais, sem um relacionamento colaborativo, não é possível alcançar um alto nível de integração interfirmas para obter maior desempenho, até porque, quanto mais estreita for a colaboração, maiores são as oportunidades dos parceiros da cadeia de fornecimento (WANG et al., 2014).

Vale ressaltar que a colaboração entre empresas pode ocorrer de diversas formas, como, por exemplo, processo de fabricação integrado, processo de distribuição integrado, processo de compartilhamento de informações. O princípio básico da colaboração é que as empresas se unam para melhorar o desempenho individual e coletivo (SARANA; MASON, 2006). Esses autores advertem, no entanto, que não é um processo natural focar o desempenho coletivo, visto que as empresas somente ficarão satisfeitas com a colaboração quando entenderem os benefícios da cooperação interfirmas.

As informações relativas às medidas de desempenho dos parceiros das relações interfirmas podem aumentar a variedade de objetivos colaborativos, uma vez que permitem o monitoramento dos resultados desejados, além de proporcionar orientações comuns, o que incentiva todos os parceiros a agirem em prol do interesse coletivo, considerando a responsabilidade que assumem pelos resultados (DEKKER; DING; GROOT, 2016). A mensuração do desempenho é utilizada nas relações interfirmas para atingir a consecução dos objetivos colaborativos, pois contribui para a mitigação e gerenciamento dos riscos associados, além do planejamento e controle (DEKKER; DING; GROOT, 2016).

Estudos prévios, como de Grafton, Abernethy e Lillis (2011), Chakraborty, Bhattacharya e Dobrykowski (2014), Schiavon (2018) e Wald et al. (2018), analisaram a relação dos objetivos colaborativos (tratados pelos estudos como redes colaborativas ou relacionamentos colaborativos) com o desempenho. Grafton, Abernethy e Lillis (2011) analisaram como fatores antecedentes influenciam as redes colaborativas em três hospitais. Examinaram até que ponto os atributos estruturais e de controle promovem a integração da atividade nas redes, considerando dentre outros aspectos, a configuração e uso da mensuração 
de desempenho e as implicações da integração para o desempenho da rede. Constaram que há tensão na configuração da rede hospitalar relacionada à obtenção de eficiência e legitimidade com a colaboração, seu compromisso com os ideais subjacentes ao mandato institucional e sua disposição em buscar colaboração efetiva sob a influência de constituintes externos.

Chakraborty, Bhattacharya e Dobrykowski (2014) objetivaram conceituar a colaboração na cadeia de suprimentos e os componentes desta cadeia na saúde (hospital), ou seja, a complexidade do relacionamento. Para os autores, a criação de valor atua como mediadora na relação entre a colaboração na cadeia de suprimentos com o desempenho da empresa. Os autores constataram que são várias as pressões relacionadas à qualidade e custos, ao mesmo tempo que as indústrias melhoraram a criação de valor por meio das compras e a gestão da cadeia de abastecimento. Por outro lado, observaram que os prestadores de cuidados de saúde têm sido lentos na sua adoção. Argumentam que essa lentidão decorre do fato de exigir colaboração, para que seja possível o compartilhamento de competências especializadas entre os atores dessa rede, o que favorecerá o desempenho futuro.

Schiavon (2018) buscou desenvolver um framework para a gestão de relacionamento com fornecedores em organizações hospitalares, além de identificar e analisar as práticas utilizadas e as dificuldades enfrentadas para a gestão de relacionamento com fornecedores em hospitais universitários públicos e privados. O estudo de caso envolveu quatro hospitais de grande porte, sendo dois públicos (autarquia e estadual) e dois privados (entidades beneficentes sem fins lucrativos). $\mathrm{O}$ autor constatou que os hospitais universitários privados estão mais à frente na implementação da gestão de relacionamentos com fornecedores, se comparados com os hospitais públicos, o que pode ser explicado em parte pelas restrições da legislação de compras públicas e carência de recursos financeiros. Schiavon (2018) inferiu que nos hospitais privados, os relacionamentos, redes ou objetivos colaborativos com os fornecedores ajudam a melhorar o seu desempenho.

Wald et al. (2018) analisaram um modelo colaborativo de assistência à saúde em uma empresa dos Estados Unidos que atuava inicialmente em duas cidades e após, com mais de 70 filiais. A empresa desenvolveu um modelo de atendimento inovador e escalável para atingir vários objetivos estratégicos: (i) criar e manter relacionamentos de alto valor que beneficiam pacientes e fornecedores; (ii) parceiros com ideias semelhantes para atuar como uma estratégia contra o desenvolvimento de redes estreitas de assistência médica e; (iii) aumentar o reconhecimento como marca nacional e internacional. Os resultados confirmaram que a empresa é considerada uma rede de relacionamentos e que os cuidados com a saúde continuam e mudam constantemente. Os fornecedores que atendem essas organizações buscam 
relacionamentos colaborativos significativos para melhor atender os pacientes, melhorar a eficiência e eficácia nos cuidados. A partir dos objetivos colaborativos, que alimentarão novos conhecimentos administrativos e clínicos, será possível melhorar o desempenho da organização. Neste sentido, formulou-se a segunda hipótese da pesquisa:

$\mathrm{H}_{2}$ : Os objetivos colaborativos influenciam positivamente nas práticas da mensuração do desempenho da cooperação comprador-fornecedor.

\subsection{Mediação das características de transação na relação entre objetivos colaborativos e mensuração do desempenho}

Dekker, Ding e Groot (2016) salientam que as características de transação medeiam a influência dos objetivos colaborativos na mensuração do desempenho, pois as características de transação refletem o ambiente interno e externo envolto nos objetivos colaborativos, e geram riscos devido as dificuldades relacionadas à complexidade do processo de mensuração do desempenho da cooperação. Ademais, o uso das informações advindas da mensuração do desempenho orienta e incentiva os parceiros para atuarem no melhor interesse dos objetivos da colaboração (DEKKER; DING; GROOT, 2016). Dekker et al. (2019), ao analisarem 200 relações comprador-fornecedor, verificaram que as redes de cooperação com escopo de transação maior, facilitam a troca de informações através das redes, mas são mais complexas de se gerenciar, por serem mais expostas aos riscos e interdependências. Contudo, a cooperação impacta positivamente no desempenho da cooperação (DEKKER et al., 2019).

Chen, Preston e Xia (2013) investigaram os fatores que influenciam o desempenho da cadeia de suprimentos hospitalar, considerando a confiança, a troca de conhecimentos e a integração de tecnologia da informação entre o hospital e seus fornecedores, ou seja, a integração hospital-fornecedor. Em uma amostra de 117 executivos da cadeia de suprimentos dos hospitais norte-americanos, os autores verificaram os efeitos diretos positivos, indiretos e moderadores entre confiança e integração de tecnologia da informação com a troca de conhecimentos, o intercâmbio de conhecimentos e da integração de tecnologia da informação com a integração hospital-fornecedor e essa com o desempenho da cadeia de suprimentos hospitalar. Concluíram que melhorar o desempenho é importante para melhorar a eficiência operacional e reduzir custos. Nesta perspectiva, formulou-se a terceira hipótese:

$\mathrm{H}_{3}$ : As características de transação entre comprador-fornecedor medeiam a relação dos objetivos colaborativos com a mensuração do desempenho da cooperação.

Dessa forma, espera-se que sejam intensificadas as práticas da mensuração do desempenho, enquanto mecanismos de acompanhamento do desempenho da cooperação, com 
o aumento da variedade de objetivos colaborativos, e que as características de transação associadas aos objetivos colaborativos medeiem esse efeito. Na Figura 1 apresenta-se o modelo teórico da pesquisa, com destaque para os construtos e as hipóteses da pesquisa.

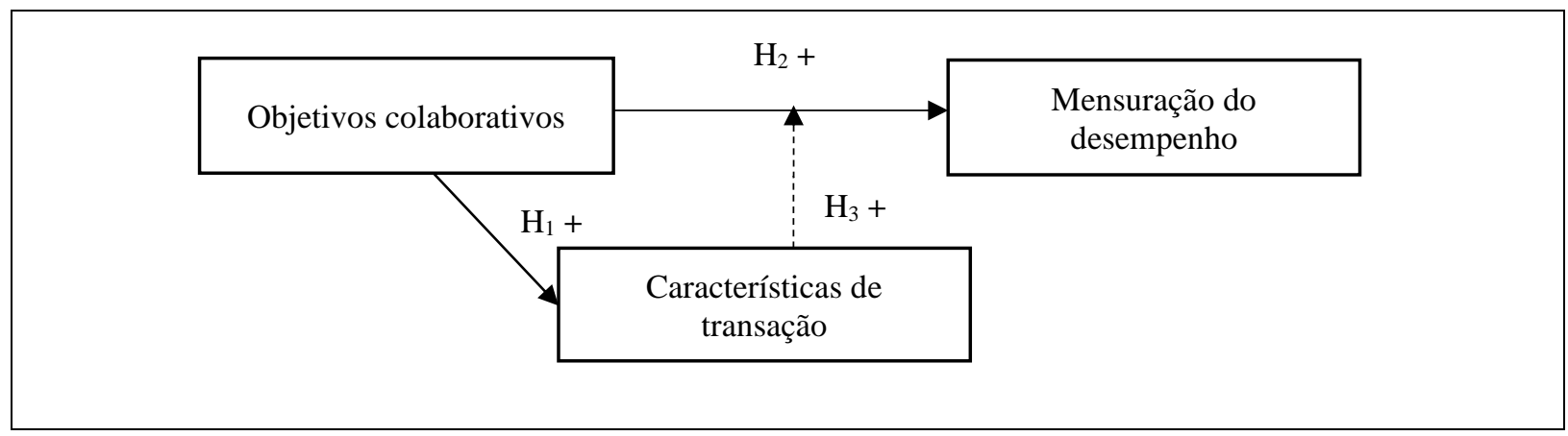

Figura 1 - Modelo teórico da pesquisa

Fonte: Elaboração própria.

A hipótese $\mathrm{H}_{1}$ prevê influência dos objetivos colaborativos nas características de transação (especificidade de ativos, interdependência de tarefas e variabilidade ambiental) entre comprador-fornecedor. Já a hipótese $\mathrm{H}_{2}$ prevê influência dos objetivos colaborativos nas práticas da mensuração do desempenho da cooperação comprador-fornecedor. Nesta hipótese, assume-se que a mensuração do desempenho é um importante mecanismo para avaliar a cooperação na consecução dos objetivos colaborativos (LANGFIELD-SMITH; SMITH, 2003; DEKKER; VAN DEN ABBEELE, 2010; SCHLOETZER, 2012). Por sua vez, a hipótese $\mathrm{H}_{3}$ prevê mediação das características de transação entre comprador-fornecedor na relação dos objetivos colaborativos com a mensuração do desempenho da cooperação.

\section{PROCEDIMENTOS METODOLÓGICOS}

Uma pesquisa de levantamento foi realizada com indivíduos que trabalham no setor de compras de hospitais de todo o Brasil. A identificação foi realizada na rede social LinkedIn a partir dos seguintes filtros: (i) "Brasil", "setor: compras" e "empresa: hospital"; (ii) "Brasil", "Atendimento médico e hospitalar" e "setor: compras"; (iii) "Brasil", "setor: comprador" e “empresa: hospital”. No total, identificaram-se 1.124 compradores, para os quais foi enviado um convite de participação da rede, sendo que 529 aceitaram o convite. Para estes foi enviado o link do questionário elaborado na plataforma Google Docs, nos meses de março a junho de 2019, obtendo-se 120 respostas válidas.

O instrumento de pesquisa (Apêndice A) compõe-se de três blocos: objetivos colaborativos; mensuração do desempenho; e características de transação. Trata-se de um 
questionário já validado no estudo de Dekker, Ding e Groot (2016), com assertivas aferidas em escala tipo Likert de sete pontos. O construto objetivos estratégicos possui 13 assertivas; o construto mensuração de desempenho 20 assertivas; e o construto características de transação 20 assertivas, sendo 10 para especificidade de ativos, 7 para variabilidade ambiental e 3 para independência de tarefas. No final do questionário, foram incluídas questões relativas à caracterização dos hospitais e perfil dos respondentes.

Os três construtos foram mensurados de acordo com os critérios utilizados no estudo de Dekker et al. (2019), que calcularam a média da soma das pontuações de cada pergunta para criar uma medida agrupada (indicador) para cada variável latente. Dessa forma, consideraramse as subcategorias criadas por Dekker et al. (2016). O construto objetivos colaborativos foi dividido em: Acesso ao Mercado (AM), Redução ao Risco (RR), Acesso aos Recursos (AR), Aprendizagem (AP) e Investimentos (IN). O construto Mensuração do desempenho foi dividido em: Desempenho Operacional (OP); Desempenho Financeiro (FIN); Desempenho do Funcionário (FUN); Desempenho de Inovação (IN). Por fim, o construto características de transação foi dividido em: Especificidade dos Ativos (EA); Variabilidade Ambiental (VA); Interdependência de Tarefas (IT).

$\mathrm{Na}$ análise dos dados, inicialmente foi realizada a análise fatorial exploratória, seguida da análise confirmatória e, na sequência, aplicou-se a técnica de modelagem de equações estruturais, por meio do software estatístico SmartPLS ${ }^{\circledR}$ versão 3.2.8. A análise fatorial exploratória visa investigar as relações existentes entre um conjunto de variáveis, a fim de identificar fatores comuns, sendo então possível estabelecer uma estrutura própria entre as variáveis investigadas (HAIR JR. et al., 2009). Por outro lado, a análise fatorial confirmatória tem a finalidade de verificar quais variáveis são consideradas para a análise dos dados, validando os construtos teóricos da pesquisa (HAIR JR. et al., 2009). Os modelos são reflexivos pelo fato de os indicadores utilizados na pesquisa serem reflexo dos construtos (HAIR JR. et al., 2009).

A modelagem de equações estruturais é uma técnica multivariada que, conforme Hair Jr. et al. (2009, p. 468), “combina aspectos de regressão múltipla (examinando relações de dependência) e análise fatorial (representando conceitos não medidos - fatores - com múltiplas variáveis) para estimar uma série de relações de dependência inter-relacionadas simultaneamente". As relações decorrem da influência de variáveis exógenas sobre variáveis endógenas, sendo que a partir do momento em que as variáveis exógenas (independentes) oscilarem, estas impactarão nas variáveis endógenas (dependentes) (BYRNE, 2001). 


\section{ANÁLISE E DISCUSSÃO DOS RESULTADOS}

\subsection{Caracterização das empresas e dos respondentes da pesquisa}

Na Tabela 1 caracterizam-se os hospitais onde os participantes da pesquisa trabalham, com destaque para o tamanho (número de leitos), natureza jurídica e atividade.

Tabela 1 - Caracterização dos hospitais

\begin{tabular}{l|c|c|l|c|c}
\hline Natureza jurídica & Quant. & \% & \multicolumn{1}{|c}{ Tamanho } & Quant. & \% \\
\hline Cooperativa & 6 & 5,00 & Baixo Porte (até 50 leitos) & 16 & 13,33 \\
Privado & 57 & 47,50 & Médio Porte (de 51 a 150 leitos) & 38 & 31,67 \\
Público municipal & 5 & 4,17 & Grande porte (de 151 a 500 leitos) & 48 & 40,00 \\
Estadual & 8 & 6,67 & Capacidade extra (acima de 500 leitos) & 10 & 8,33 \\
Federal & 2 & 1,67 & Não informado & 8 & 6,67 \\
\cline { 4 - 6 } Confessional & 1 & 0,83 & Total & $\mathbf{1 2 0}$ & $\mathbf{1 0 0 \%}$ \\
\cline { 4 - 7 } Filantrópico & 32 & 26,67 & \multicolumn{1}{|c}{ Atividade } & 33 & 27,5 \\
Universitário & 6 & 5,00 & Média complexidade & 87 & 72,5 \\
Outros & 3 & 2,50 & Alta complexidade & $\mathbf{1 2 0}$ & $\mathbf{1 0 0 \%}$ \\
\hline Total & $\mathbf{1 2 0}$ & $\mathbf{1 0 0 \%}$ & Total & &
\end{tabular}

Fonte: Dados da pesquisa.

Nota-se na Tabela 1 que, em relação a natureza jurídica dos hospitais onde os respondentes da pesquisa trabalham, houve prevalência de hospitais privados $(47,5 \%)$ e hospitais filantrópicos $(26,67 \%)$. No que diz respeito ao tamanho, $40 \%$ dos respondentes atuam em hospitais de grande porte, de 151 a 500 leitos; e 10 respondentes $(8,33 \%)$ trabalham em hospitais com capacidade extra (acima de 500 leitos). Ressalta-se que quanto maior o hospital, mais compras são necessárias, o que eleva a complexidade desse tipo de organização. Quanto à atividade dos hospitais, quando os respondentes assinalavam mais de uma alternativa foi considerada a de maior complexidade. A maioria $(72,5 \%)$ dos participantes da pesquisa atua em hospitais com atividades de alta complexidade, sendo que nenhum possui somente atividades de baixa complexidade, o que indica que tais organizações investem em tecnologia e procedimentos que exigem serviços mais qualificados.

$\mathrm{Na}$ Tabela 2 apresenta-se o perfil dos respondentes da pesquisa, com ênfase na área de maior formação acadêmica, a função atual no setor de compras, a experiência de trabalho, o tempo que atuam na função atual e a experiência de trabalho anterior nessa função.

Tabela 2 - Perfil dos respondentes da pesquisa

\begin{tabular}{l|c|c|l|c|c}
\multicolumn{1}{c|}{ Formação acadêmica } & Quant. & \% & Função no setor de compras & Quant. & \% \\
\hline Administrativa & 89 & 74,17 & Assistente/Auxiliar & 22 & 18,33 \\
Assistencial & 13 & 10,83 & Analista & 40 & 33,33 \\
Outras áreas & 16 & 12,50 & Coordenador & 19 & 15,83 \\
Sem formação & 3 & 2,50 & Supervisor & 8 & 6,67 \\
\cline { 1 - 2 } Total & $\mathbf{1 2 0}$ & $\mathbf{1 0 0 \%}$ & Gestor/Líder/Gerente & 21 & 17,50 \\
\cline { 1 - 5 } Experiência de trabalho & & Outro & 10 & 8,33 \\
\hline
\end{tabular}




\begin{tabular}{|c|c|c|c|c|c|}
\hline Até 5 anos & 30 & 25,00 & Total & 120 & $100 \%$ \\
\hline De 5,01 a 10 anos & 40 & 33,33 & Experiência antes na função & & \\
\hline De 10,01 a 15 anos & 23 & 19,17 & Sem experiência anterior/função & 34 & 28,33 \\
\hline De 15,01 anos a 20 anos & 16 & 13,33 & Até 5 anos & 52 & 43,33 \\
\hline Acima de 20 anos & 11 & 9,17 & De 5,01 a 10 anos & 20 & 16,67 \\
\hline Total & 120 & $100 \%$ & De 10,01 a 15 anos & 9 & $7,50 \%$ \\
\hline Tempo na atual função & & & De 15,01 anos a 20 anos & 4 & $3,33 \%$ \\
\hline Até 5 anos & 79 & 65,83 & Acima de 20 anos & 1 & $0,83 \%$ \\
\hline De 5,01 a 10 anos & 21 & 17,50 & Total & 120 & $100 \%$ \\
\hline De 10,01 a 15 anos & 13 & 10,83 & & & \\
\hline De 15,01 anos a 20 anos & 3 & 2,50 & & & \\
\hline Acima de 20 anos & 4 & 3,33 & & & \\
\hline Total & 120 & $100 \%$ & & & \\
\hline
\end{tabular}

Fonte: Dados da pesquisa.

De acordo com a Tabela 2 , a maioria dos respondentes $(74,17 \%)$ possui formação acadêmica na área administrativa, o que se justifica por ser um cargo que exige habilidades e conhecimentos de gestão, especialmente negociação. Os três respondentes sem formação acadêmica (dois assistentes/auxiliares e um comprador) estão pouco tempo na função atual (menos de dois anos) e é possível que estejam buscando uma formação acadêmica. A função que mais se destacou pela quantidade de respostas é de analista $(33,33 \%)$. Em relação à experiência de trabalho dos participantes da pesquisa, destaca-se a faixa entre 5 e 10 anos $(33,33 \%)$ e até 5 anos (25\%) de experiência. Quanto ao tempo que trabalham na função atual, $65,83 \%$ dos respondentes indicaram estar menos de 5 anos na função. Em relação à experiência de trabalho anterior na função, 43,33\% apontaram ter experiência de até 5 anos. Em geral, depreende-se que, em sua maioria, os respondentes são profissionais jovens.

\subsection{Estatística descritiva}

$\mathrm{Na}$ Tabela 3 constam as estatísticas descritivas das questões relativas aos objetivos colaborativos, mensuração do desempenho e características de transação, por indicador.

Tabela 3 - Estatísticas descritivas das variáveis dos respectivos construtos

\begin{tabular}{l|c|c|c|c}
\hline \multicolumn{5}{c}{ Objetivos colaborativos } \\
\hline Indicadores & Mínimo & Máximo & Média & Desvio Padrão \\
\hline Redução ao Risco & 1,33 & 7 & 5,6 & 1,168 \\
Acesso ao Mercado & 1 & 7 & 4,6 & 1,363 \\
Acesso aos Recursos & 1 & 7 & 5,3 & 1,149 \\
Investimentos & 1 & 7 & 5,3 & 1,272 \\
Aprendizagem & 1 & 7 & 5,8 & 1,162 \\
\hline \multicolumn{5}{c}{ Mensuração do desempenho } \\
\hline Indicadores & Mínimo & Máximo & Média & Desvio Padrão \\
\hline Operacional & 4 & 7 & 6,1 & 0,663 \\
Financeiro & 1 & 7 & 5,5 & 1,332 \\
Funcionário & 2,5 & 7 & 6,1 & 0,954 \\
Inovação & 2,5 & 7 & 5,8 & 1,044 \\
\hline
\end{tabular}




\begin{tabular}{l|c|c|c|c}
\hline \multicolumn{5}{c}{ Características de transação } \\
\hline Indicadores & Mínimo & Máximo & Média & Desvio Padrão \\
\hline Especificidade dos Ativos & 1 & 7 & 4,1 & 1,226 \\
Variabilidade Ambiental & 2,71 & 7 & 5,1 & 1,134 \\
Interdependência de Tarefas & 3,33 & 7 & 5,8 & 1,014 \\
\hline
\end{tabular}

Fonte: Dados da pesquisa.

Verifica-se na Tabela 3 que, nas perguntas sobre os objetivos colaborativos, houve respostas nos dois extremos, o que sugere opiniões divergentes em relação à importância desses critérios, ou seja, os respondentes indicaram que as redes de colaboração comprador-fornecedor no hospital em que trabalham são desde pouco importante até muito importante. Contudo, em sua maioria, os participantes consideram que a rede de colaboração comprador-fornecedor seja importante, uma vez que a média ficou entre 4,6 e 5,8, com desvio padrão na marca de 1 para cima ou para baixo, o que denota que não houve muita variabilidade nas respostas.

No construto mensuração do desempenho foi atribuída importância maior pelos respondentes para os indicadores do desempenho operacional (custos, qualidade dos produtos/serviços, satisfação do cliente, utilização da capacidade, produtividade no trabalho, tempo de entrega, número de lançamentos de novos produtos/serviços e custo por funcionário), pois o valor mínimo foi 4 , o que sugere que os respondentes consideram esses critérios relevantes na relação comprador-fornecedor para o hospital. Mensuração do desempenho do funcionário e de inovação obtiveram valores mínimos entre 2 e 3. Chama a atenção que respondentes indicaram que o desempenho financeiro é pouco importante (valor 1) na relação comprador-fornecedor. Por outro lado, todos os indicadores de mensuração do desempenho obtiveram indicações no outro extremo da escala (valor 7), que são muito importantes para a organização.

Com relação ao construto características de transação, o valor máximo (7) foi atribuído para todos os indicadores, enquanto que os valores mínimos variaram de 1 (especificidade dos ativos), ficando próximo a 3 para variabilidade ambiental e entre 3 e 4 para interdependência de tarefas. Isto indica que alguns consideram que a cooperação comprador-fornecedor em relação aos ativos é muito fácil para alguns e muito difícil para outros. A média variou de $4 \mathrm{a}$ 6, denotando que é mais difícil que os ativos sejam fornecidos nessa cooperação. O desvio padrão demonstrou não haver muita variância em relação à média, distância próxima a 1 .

No comparativo dos três construtos, percebe-se que os indicadores do construto mensuração do desempenho apresentam médias superiores, o que indica que é atribuída maior importância para esses indicadores, se comparados aos objetivos colaborativos e às características de transação. De acordo com Mahama (2006), a mensuração do desempenho 
auxilia as organizações na tomada de decisões corretivas, na redução de incertezas e na promoção da aprendizagem organizacional, o que pode refletir nos objetivos colaborativos e nas características de transação. Ainda em relação à mensuração do desempenho, o desvio padrão ficou próximo a 1 e em alguns casos, como no desempenho operacional e financeiro, abaixo (respectivamente 0,663 e 0,954), o que indica que houve menor variação das respostas nesse indicador, reforçando a importância atribuída (média 6,1 em ambos os indicadores).

\subsection{Modelo de mensuração}

A validação do modelo de mensuração teve por base os passos recomendados por Hair Jr. et al. (2009), iniciando pela análise das cargas externas e a Average Variance Extracted (AVE) para verificação da validade convergente. Para análise de consistência interna, analisouse a Composite Reliability (CR). Em consonância com Hair Jr. et al. (2009), os indicadores AVE e CR são considerados aceitáveis se a carga fatorial for superior a 0,5 e 0,7 , respectivamente. Na Tabela 4 são evidenciados os resultados das correlações de variáveis latentes de primeira ordem, indicando também os resultados da CR e da AVE.

Tabela 4 - Correlações de variáveis latentes de primeira ordem

\begin{tabular}{lccc}
\hline & 1 & 2 & 3 \\
\hline 1. CT & $\mathbf{0 , 8 1 1}$ & & \\
2. MD & 0,492 & $\mathbf{0 , 9 0 1}$ & $\mathbf{0 , 8 3 5}$ \\
3. OC & 0,519 & 0,827 & 0,919 \\
\hline Composite Reliability (CR) & 0,793 & 0,928 & 0,697 \\
Average Variance Extracted (AVE) & 0,658 & 0,811 & \\
\hline
\end{tabular}

Nota: Os valores na diagonal são as raízes quadradas dos desvios médios extraídos. CR > 0.7; AVE > 0.5. Legenda: $\mathrm{OC}=$ Objetivos colaborativos; $\mathrm{CT}=$ Características de transação; $\mathrm{MD}=$ Mensuração do desempenho. Fonte: Dados da pesquisa.

O modelo de mensuração foi validado após três rodadas de testes e exclusões dos indicadores até obter validação e confiabilidade dos construtos. Seguiram-se os passos sugeridos por Hair Jr. et al. (2009), portanto, ao invés de eliminar automaticamente os valores que apresentavam carga externa abaixo de 0,7 foi analisada a remoção dos itens de acordo com a confiabilidade composta e a validade do conteúdo do construto. Assim, foram excluídos características de transação - especificidade dos ativos (CT_EA) na rodada 1 e mensuração do desempenho - financeiro (MD_FIN) na rodada 2, por não terem atingido os critérios de validade discriminante, pois apresentaram alto nível de cargas cruzadas (HAIR JR. et al., 2009).

A validade discriminante foi analisada a partir das cargas cruzadas (indicadores de nível) e do critério de Fornell-Larcker. As raízes quadradas da AVE (valores da diagonal) foram superiores às correlações entre as variáveis latentes (valores fora da diagonal). Isso indica que as medidas são diferentes para cada construto, confirmando a validade discriminante das 
variáveis (HAIR JR. et al., 2009). Os indicadores da CR e da AVE apresentam resultados acima do mínimo sugerido pela literatura. Na Tabela 5 são evidenciados os resultados do modelo ajustado (após a exclusão dos itens necessários para a confiabilidade), a partir da matriz de cargas fatoriais entre os itens e variáveis latentes.

Tabela 5 - Matriz de cargas fatoriais

\begin{tabular}{l|c|ccc}
\hline \multicolumn{1}{c}{ CT } & MD & OC & VIF \\
\hline CT_IT & $\mathbf{0 , 8 6 0}$ & 0,461 & 0,451 & 1,115 \\
CT_VA & $\mathbf{0 . 7 6 0}$ & 0,326 & 0,388 & 1,115 \\
MD_FUN & 0,371 & $\mathbf{0 , 8 9 4}$ & 0,751 & 2,417 \\
MD_IN & 0,496 & $\mathbf{0 , 9 2 1}$ & 0,764 & 2,907 \\
MD_OP & 0,463 & $\mathbf{0 , 8 8 7}$ & 0,719 & 2,355 \\
OC_AM & 0,361 & 0,404 & $\mathbf{0 , 6 9 9}$ & 1,731 \\
OC_AP & 0,494 & 0,877 & $\mathbf{0 , 8 7 2}$ & 2,664 \\
OC_AR & 0,458 & 0,638 & $\mathbf{0 , 8 3 7}$ & 2,410 \\
OC_IN & 0,447 & 0,708 & $\mathbf{0 , 9 0 3}$ & 3,330 \\
OC_RR & 0,392 & 0,717 & $\mathbf{0 , 8 4 8}$ & 2,515 \\
\hline
\end{tabular}

Legenda: $\mathrm{CT}=$ Características de Transação; IT = Interdependência de Tarefas; VA = Variabilidade Ambiental; $\mathrm{MD}=$ Mensuração do desempenho; FUN = Funcionário; $\mathrm{IN}=$ Investimento; $\mathrm{OP}=$ Operacional; $\mathrm{OC}=$ Objetivos colaborativos; $\mathrm{AM}=$ Acesso ao mercado; $\mathrm{AP}=$ Aprendizagem; $\mathrm{AR}=$ Acesso aos recursos; $\mathrm{IN}=$ Investimentos; RR = Redução de risco; VIF: Variance Inflation Factor.

Fonte: Dados da pesquisa.

Na Tabela 5 é possível visualizar que as cargas fatoriais estão acima de 0,5 e não há nenhum indicador que esteja altamente correlacionado. $\mathrm{O}$ indicador com maior $\operatorname{VIF}(3,330)$ foi objetivos colaborativos - investimentos (OC_IN), mas está dentro do limite de 5 considerado aceitável por Hair Jr. et al (2009), o que indica que não há presença de multicolinearidade. Assim, com base nos resultados de confiabilidade, os construtos possuem limites aceitáveis para o teste do modelo estrutural.

\subsection{Modelo estrutural}

Depois da validação do modelo de mensuração, seguiram-se os passos definidos por Hair Jr. et al. (2009) para avaliar o modelo estrutural. Inicialmente foi considerado o resultado do $\mathrm{R}^{2}$, que se refere ao poder explicativo do modelo, isto é, o percentual da variância da variável latente (dependente) explicado pelas variáveis independentes (HAIR JR. et al., 2009). Consideraram-se os percentuais indicados por Cohen (2013) para análise do $\mathrm{R}^{2}$ ajustado (adj.) nas Ciências Sociais: (i) próximo de $2 \%$, explicação baixa; (ii) próximo a $13 \%$, explicação média; e (iii) acima de 26\%, explicação alta. Ainda de acordo com Cohen (2013), no que tange ao tamanho do efeito analisado pelo $\mathrm{f}^{2}$ tem-se que: (i) 0,02 é pequeno; (ii) 0,15 é médio; e (iii) 0,35 é grande. Para analisar a intensidade do coeficiente estrutural ( $\beta$ ), Hair Jr. et al. (2009) sugerem que: (i) <0,35 baixo; (ii) 0,35 a 0,6 médio; e (iii) >0,6 alto.

A significância entre indicadores e variáveis latentes foi obtida a partir do bootstraping 
no software SmartPLS ${ }^{\circledR}$ calculada com 5.000 subamostras. Na Tabela 6 apresentam-se os resultados do modelo estrutural.

Tabela 6 - Modelo estrutural

\begin{tabular}{c|c|c|c|c|c|c}
\hline Relações estruturais & Hipóteses & $\begin{array}{c}\text { Coeficiente } \\
\text { estrutural }\end{array}$ & Estatística t & P Value & $\mathrm{f}^{2}$ & $\mathrm{R}^{2}$ adj. \\
\hline OC $\rightarrow$ CT & $\mathrm{H}_{1}$ & 0,519 & 8,123 & $0,000 * * *$ & 0,369 & 0,264 \\
OC $\rightarrow$ MD & $\mathrm{H}_{2}$ & 0,783 & 13,657 & $0,000 * * *$ & 1,442 & 0,684 \\
OC $\rightarrow$ CT $\rightarrow$ MD & $\mathrm{H}_{3}$ & 0,045 & 1,048 & 0,295 & - & - \\
\hline
\end{tabular}

Notas: Significância ao nível de ***1\%.

Legenda: $\mathrm{OC}=$ Objetivos colaborativos $; \mathrm{CT}=$ Características de transação; $\mathrm{MD}=$ Mensuração do desempenho. Fonte: Dados da pesquisa.

De acordo com a Tabela 6, tanto a $\mathrm{H}_{1}$ como a $\mathrm{H}_{2}$ apresentaram coeficiente estrutural positivo, respectivamente de 0,519 e 0,783 , sendo que a intensidade do coeficiente da $\mathrm{H}_{1}$ pode ser considerado médio (de 0,35 a 0,6 ) e da $\mathrm{H}_{2}$ alto $(>0,6)$. Já o coeficiente estrutural da $\mathrm{H}_{3}$ foi de 0,045, o que conforme Hair Jr. et al. (2009) caracteriza-se como baixo $(<0,35)$. O poder explicativo do modelo ( $\mathrm{R}^{2}$ adj.) indica que as variáveis que integram os objetivos colaborativos explicam $26 \%$ das características de transação e $68 \%$ da mensuração do desempenho, o que representa um poder explicativo alto (acima de 26\%). Nos dois casos a explicação é alta, ou seja, acima de $26 \%$ de acordo com Cohen (2013).

Tanto o R-quadrado ajustado ( $\mathrm{R}^{2}$ adj.) quanto o coeficiente do tamanho de efeito $\left(\mathrm{f}^{2}\right)$ são utilizados para comparar diferentes amostras ou subamostras, a fim de analisar o impacto de uma variável independente na variável dependente. Em relação ao tamanho do efeito $\left(\mathrm{f}^{2}\right)$, temse que a $\mathrm{H}_{1}$ e a $\mathrm{H}_{2}$ apresentaram efeito grande. A estatística t, quando acima de 1,96 indica que o modelo pode ser aceito e os resultados discutidos. A hipótese $\mathrm{H}_{3}$, que testa a mediação, não atingiu o mínimo necessário para que pudesse ser discutida a influência, ao passo que a $\mathrm{H}_{1}$ e a $\mathrm{H}_{2}$ apresentaram resultados acima de 1,96.

As hipóteses $\mathrm{H}_{1}$ e $\mathrm{H}_{2}$ indicam relação direta e a $\mathrm{H}_{3}$ mediação. A relação direta entre objetivos colaborativos e características de transação foi estatisticamente significante ao nível de $1 \%(\mathrm{p}<0,05)$, o que suporta não se rejeitar a $\mathrm{H}_{1}$. Da mesma forma, a relação direta entre objetivos colaborativos e mensuração do desempenho foi estatisticamente significante ao nível de $1 \%(\mathrm{p}<0,05)$, o que suporta não se rejeitar a $\mathrm{H}_{2}$. Contudo, a relação indireta entre objetivos colaborativos e mensuração do desempenho, mediada pelas características de transação, não foi estatisticamente significante $(0,295)$, assim rejeita-se a hipótese $\mathrm{H}_{3}$.

\subsection{Discussão dos resultados}


Os resultados da pesquisa indicam que as redes de colaboração são importantes para as organizações hospitalares, visto que os objetivos colaborativos apresentaram relação positiva e significativa com a mensuração do desempenho e as características de transação. Os objetivos colaborativos, por vezes, não dependem de um único indivíduo e uma única organização, dependem do compartilhamento entre parceiros. Na organização hospitalar representam: acesso ao mercado com vistas em atrair mais pacientes; reduzir o risco ao estabilizar os ganhos e aumentar a capacidade hospitalar; acesso aos recursos que o hospital não possui (materiais, tecnologia e compartilhamento de conhecimentos); investimentos por meio do compartilhamento e superação das barreiras comerciais; aprendizagem sobre as práticas de negócios locais, habilidades de gerenciamento e acesso à redes de negócios.

A influência dos objetivos colaborativos nas características de transação está implicada com a variabilidade ambiental e a interdependência de tarefas, sendo que a primeira refere-se às mudanças no ambiente de colaboração e a segunda à execução de tarefas na rede de colaboração. Os resultados da pesquisa denotam que o ambiente dos hospitais mudou quanto às atividades de fornecedores e preferências dos clientes, no que concerne ao preço, qualidade e confiabilidade. Dekker, Ding e Groot (2016) advertem que as relações colaborativas mais relevantes enfrentam maior variabilidade ambiental, como consequência da exposição a fatores externos, como, por exemplo, preferências do cliente, atividades de mercado dos concorrentes, desenvolvimento de novos produtos ou serviços, entre outros. Mudou também no que tange ao desenvolvimento tecnológico (p. ex.: tecnologias de diagnóstico e tratamento), atividades de mercados concorrentes, condições macroeconômicas e políticas governamentais. Os respondentes ressaltaram que as atividades de cooperação exigem continuidade da parceria e favorecem a geração de conhecimento especializado e experiência, o que demanda tempo e esforços.

Quanto à mensuração do desempenho, tem-se que o desempenho operacional, do funcionário e de inovação relacionam-se diretamente e são importantes para avaliar o desempenho da cooperação comprador-fornecedor dos hospitais. Custos, qualidade dos produtos e serviços, satisfação do cliente, utilização da capacidade, produtividade no trabalho, tempo de entrega, lançamento de novos produtos e custo por funcionário compõem o desempenho da operação. Dekker, Ding e Groot (2016) explicam que informações de mensuração do desempenho da cooperação ganham importância a partir da maior troca de informações operacionais com a rede de colaboração. Já a lealdade, treinamento, satisfação dos funcionários e qualidade dos serviços pós-venda dizem respeito ao desempenho do funcionário, que, de acordo com Dekker, Ding e Groot (2016), podem fidelizar os mesmos e melhorar a rede 
de colaboração comprador-fornecedor pela experiência que possuem.

Por fim, a introdução oportuna de novos produtos e serviços, o número de melhorias relacionadas e melhorias no sistema, além da transferência de tecnologia, estão atrelados ao desempenho de inovação. Em relação ao desempenho de inovação, Dekker, Ding e Groot (2016) ressaltam que é importante compartilhar e investir conjuntamente no desenvolvimento de novas tecnologias, no conhecimento do mercado local. Até porque, para os autores, o sucesso colaborativo depende da inovação bem-sucedida, o que aumenta a integração e alinhamento dos recursos e das contribuições de ambos os parceiros da rede, como no caso desta pesquisa, entre compradores e fornecedores de hospitais.

Estes resultados do modelo estrutural suportam não se rejeitar as duas primeiras hipóteses da pesquisa. $\mathrm{A} \mathrm{H}_{1}$, que prevê influência positiva entre os objetivos colaborativos e as características de transação, não foi rejeitada. Isso indica que há influência dos objetivos colaborativos na variabilidade do ambiente e na interdependência das tarefas no setor de compras de hospitais, ou seja, os participantes da pesquisa entendem que a cooperação é uma estratégia adotada pelo setor de compras e está associada com as características de transação. Os resultados estão alinhados com os de Correia (2001), que analisou as características de transação em organizações da saúde e verificou que o relacionamento colaborativo compradorfornecedor, no longo prazo, assegura a estratégia de produção e considera que as estratégias de compras devem estar alinhadas com a estratégia competitiva da empresa.

A influência dos objetivos colaborativos nas características de transação é corroborada por Oxley e Sampson (2004), Anderson e Dekker (2005; 2014) e Dekker, Ding e Groot (2016). De acordo com Oxley e Sampson (2004) e Anderson e Dekker (2005), as decisões relativas às tarefas interdependentes (características de transação) condicionam os resultados e ações do parceiro da cooperação aos resultados e ações do outro, o que denota a importância dos objetivos colaborativos. Anderson e Dekker (2014) observaram que as transações das empresas geralmente são precedidas de negociações entre os parceiros, por acreditarem que isso trará benefícios para ambos, o que fortalece a rede colaborativa, no caso desta pesquisa, em hospitais. Dekker, Ding e Groot (2016) constataram que quanto maior a importância estratégica da colaboração, maior será a vontade de investir, o que envolve características de transação, o que também pode ocorrer no setor de compras de hospitais.

A hipótese $\mathrm{H}_{2}$, que prevê influência dos objetivos colaborativos nas práticas da mensuração do desempenho da cooperação comprador-fornecedor, também teve suporte para a não rejeição. Isso indica que os respondentes entendem que a colaboração compradorfornecedor no setor de compras de hospitais influencia nas práticas da mensuração do 
desempenho (operacional, do funcionário e de inovação). Tal influência foi corroborada nos estudos em hospitais por Chakraborty, Bhattacharya e Dobrykowski (2014), Schiavon (2018) e Wald et al. (2018).

Langfield-Smith e Smith (2003), Dekker e Van Den Abbeele (2010) e Schloetzer (2012) observaram que a mensuração do desempenho é um importante mecanismo para acompanhar os resultados e avaliar o relacionamento interfirmas na consecução dos objetivos individuais e coletivos. Dekker (2004) aduz que isso facilita a comunicação e resolução de problemas, o que ajuda a explicar os resultados desta pesquisa. As redes colaborativas fornecem informações relevantes às parceiras, com o intuito de obter resultados satisfatórios (MAHAMA, 2006; REUER; KLIJN; LIOUKAS, 2014; DEKKER; SAKAGUCHI; KAWAI, 2013).

A hipótese $\mathrm{H}_{3}$ foi rejeitada, pois não se encontrou mediação das características de transação entre comprador-fornecedor na relação dos objetivos colaborativos com mensuração do desempenho da cooperação. Diferente do observado nesta pesquisa, Chen, Preston e Xia (2013) encontraram relação positiva e observaram que a melhoria do desempenho da cadeia de suprimentos hospitalar é fundamental nas organizações de saúde, devido a relação de algumas características corporativas dos hospitais, atreladas aos objetivos colaborativos da cadeia de suprimentos. Dekker et al. (2019) constataram que redes de cooperação facilitam a troca de informações, ao mesmo tempo que são mais complexas de gerenciar e mais expostas às interdependências de tarefas (características de transação) e riscos, mas impactam positivamente no desempenho, o que diverge dos achados do presente estudo.

De forma geral, os resultados indicam que no setor de compras dos hospitais pesquisados, os objetivos colaborativos entre comprador-fornecedor podem ser ainda mais importantes a depender das características de transação e da mensuração do desempenho das organizações envolvidas na cooperação, que são influenciadas por esses objetivos colaborativos.

\section{CONCLUSÕES}

Este estudo analisou a influência dos objetivos colaborativos nas práticas da mensuração do desempenho da cooperação, mediada pelas características de transação do setor de compras de hospitais. Os resultados revelaram que os objetivos colaborativos influenciam as características de transação da relação comprador-fornecedor e a mensuração do desempenho da cooperação. Isso melhora a comunicação, o compartilhamento de conhecimentos e competências e a resolução conjunta de problemas, o que coaduna com os objetivos da colaboração. 
A principal contribuição da pesquisa está em oferecer evidências empíricas de que os objetivos colaborativos (acesso ao mercado, redução dos riscos, acesso aos recursos, investimentos e aprendizagem) influenciam as características de transação (variabilidade ambiental e interdependência de tarefas). E que as redes de colaboração influenciam as práticas da mensuração do desempenho (operacional, do funcionário e de inovação). Assim, quanto mais objetivos colaborativos houver no setor de compras de hospitais, menos arriscados serão as características de transação relativas à variabilidade ambiental (menos mudanças no ambiente), maior será a execução de tarefas (interdependência) na rede colaborativa, e mais objetivos de colaboração influenciam as práticas de mensuração do desempenho da cooperação.

Esta pesquisa contribui para a lacuna percebida e apontada no estudo de Dekker, Ding e Groot (2016), em que destacam a necessidade de pesquisas que analisem o alinhamento dos objetivos colaborativos com as características de transação e a mensuração do desempenho das relações de interação. Dessa forma, o estudo no setor de compras de hospitais revelou que há relação direta dos objetivos colaborativos com as características de transação e dos objetivos colaborativos com a mensuração do desempenho. Entretanto, ao rejeitar a hipótese de que as características de transação medeiam a relação dos objetivos colaborativos com a mensuração do desempenho da cooperação, ficou indicado que, no campo investigado, as características de transação não explicam a influência da colaboração comprador-fornecedor na mensuração do desempenho da cooperação.

As implicações práticas do estudo relacionam-se com os profissionais do setor de compras e com os próprios hospitais onde estes trabalham. Souza et al. (2009) já alertavam que no controle de gestão em hospitais, como no caso do setor de compras, é imprescindível a avaliação da eficiência, tendo em vista a responsabilidade com diversas questões, como ausência de produtos e prazos de validade. Tontini et al. (2016) ressaltam que é preciso melhorar cada vez mais a forma de lidar com diferentes questões relacionadas ao setor, pois em hospitais o reflexo poderá ser notado no paciente atendido, e quando isso não ocorre com a devida atenção e cuidado, a relação comprador-fornecedor poderá colocar vidas em risco.

Os achados deste estudo podem contribuir, no sentido de os hospitais darem maior atenção ao setor de compras. Organizações hospitalares, que optarem pela promoção da cooperação comprador-fornecedor, podem melhorar os seus processos, sendo possível criar vantagem competitiva e, consequentemente, criar valor. Além de melhorar o desempenho, favorece a realização de mudanças com vistas em melhorias do ambiente e das tarefas executadas. Além dos benefícios já elucidados, Das e Teng (1996) e Kale e Singh (2007) citam que a colaboração interfirmas pode trazer uma melhor posição das organizações no mercado, 
acesso mais fácil a recursos e aprendizagem organizacional.

O estudo apresenta algumas limitações, decorrentes principalmente da estratégia de pesquisa adotada. Assim, recomenda-se que, em estudos futuros, sejam realizadas pesquisas aprofundadas e com abordagem qualitativa, para analisar os laços prévios e outras características que são difíceis de serem mensuradas e analisadas quantitativamente, de modo a abranger a compreensão de informações que podem ser relevantes para a temática investigada. Estudos futuros também podem considerar outros construtos, como a especificidade dos ativos e o desempenho financeiro, não considerados nesta pesquisa por conta do modelo utilizado. Recomenda-se ainda investigar outras organizações de saúde, não somente hospitais, para comparar os resultados.

\section{REFERÊNCIAS}

ABREU, A.; MACEDO, P.; CAMARINHA-MATOS, L.M. Elements of a methodology to assess the alignment of core-values in collaborative networks. International Journal of Production Research, v. 47, n. 17, p. 4907-4934, 2009.

ANDERSON, S.W.; DEKKER, H.C. The role of management controls in transforming firm boundaries and sustaining hybrid organizational forms. Foundations and Trends ${ }^{\circledR}$ in Accounting, v. 8, n. 2, p. 75-141, 2014.

ANDERSON, S.W.; DEKKER, H.C. Management control for market transactions: The relation between transaction characteristics, incomplete contract design, and subsequent performance. Management Science, v. 51, n. 12, p. 1734-1752, 2005.

BYRNE, B.M. Structural equation modeling with AMOS: Basic concepts, applications, and programming. New Jersey: Lawrence Erlbaum Associates Publishers, 2001.

CHAKRABORTY, S.; BHATTACHARYA, S.; DOBRZYKOWSKI, D.D. Impact of supply chain collaboration on value co-creation and firm performance: a healthcare service sector perspective. Procedia Economics and Finance, v. 11, n. 7, p. 676-694, 2014.

CHEN, D.Q.; PRESTON, D.S.; XIA, W. Enhancing hospital supply chain performance: A relational view and empirical test. Journal of Operations Management, v. 31, n. 6, p. 391408, 2013.

COHEN, J. Statistical power analysis for the behavioral sciences. 2. ed. United States of America: Lawrence Erlbaum Associates, 2013. 
COMBS, J.G.; KETCHEN JR, D.J. Explaining interfirm cooperation and performance: toward a reconciliation of predictions from the resource-based view and organizational economics. Strategic Management Journal, v. 20, n. 9, p. 867-888, 1999.

CORREIA, G.M.A utilização do conceito de custos de transação na seleção de fornecedores de insumos produtivos na indústria farmacêutica. 2001. 178 f. Dissertação (Mestrado em Engenharia de Produção) - Escola Politécnica, Universidade de São Paulo, São Paulo, 2001.

DAS, T.K.; TENG, B.-S. Risk types and inter-firm alliance structures. Journal of Management Studies, v. 33, n. 6, p. 827-843, 1996.

DEKKER, H.C. Control of inter-organizational relationships: evidence on appropriation concerns and coordination requirements. Accounting, Organizations and Society, v. 29, n. 1, p. 27-49, 2004.

DEKKER, H.C. On the boundaries between intrafirm and interfirm management accounting research. Management Accounting Research, v. 31, n. 2, p. 86-99, 2016.

DEKKER, H.C.; DING, R.; GROOT, T. Collaborative performance management in interfirm relationships. Journal of Management Accounting Research, v. 28, n. 3, p. 25-48, 2016.

DEKKER, H.C.; DONADA, C.; MOTHE, C.; NOGATCHEWSKY, G. Boundary spanner relational behavior and inter-organizational control in supply chain relationships. Industrial Marketing Management, v. 77, n. 2, p. 143-154, 2019.

DEKKER, H.C.; SAKAGUCHI, J.; KAWAI, T. Beyond the contract: Managing risk in supply chain relations. Management Accounting Research, v. 24, n. 2, p. 122-139, 2013.

DEKKER, H.C.; VAN DEN ABBEELE, A. Organizational learning and interfirm control: The effects of partner search and prior exchange experiences. Organization Science, v. 21, n. 6, p. 1233-1250, 2010.

DYER, J.H.; SINGH, H. The relational view: Cooperative strategy and sources of interorganizational competitive advantage. Academy of Management Review, v. 23, n. 4, p. 660-679, 1998.

FYALL, A.; GARROD, B.; WANG, Y. Destination collaboration: A critical review of theoretical approaches to a multi-dimensional phenomenon. Journal of Destination Marketing \& Management, v. 1, n. 1, p. 10-26, 2012.

GEYSKENS, I.; STEENKAMP, J.-B.E.M.; KUMAR, N. Make, buy, or ally: A transaction cost 
theory meta-analysis. Academy of Management Journal, v. 49, n. 3, p. 519-543, 2006.

GLAISTER, K.W.; BUCKLEY, P.J. Strategic motives for international alliance formation. Journal of Management Studies, v. 33, n. 3, p. 301-332, 1996.

GRAFTON, J.; ABERNETHY, M.A.; LILLIS, A.M. Organisational design choices in response to public sector reforms: A case study of mandated hospital networks. Management Accounting Research, v. 22, n. 4, p. 242-268, 2011.

GROOT, T.L.C.M; MERCHANT, K. A. Control of international joint ventures. Accounting, Organizations and Society, v. 25, n. 6, p. 579-607, 2000.

HAGEDOORN, J. Understanding the rationale of strategic technology partnering: Nterorganizational modes of cooperation and sectoral differences. Strategic Management Journal, v. 14, n. 5, p. 371-385, 1993.

HAIR Jr., J.F.; BLACK, W.C.; BABIN, B.J.; ANDERSON, R.E.; TATHAM, R.L. Análise Multivariada de Dados. 6. ed. Porto Alegre: Bookman, 2009.

ITTNER, C.D.; LARCKER, D.F.; RANDALL, T. Performance implications of strategic performance measurement in financial services firms. Accounting, Organizations and Society, v. 28, n. 7, p. 715-741, 2003.

KALE, P.; SINGH, H. Building firm capabilities through learning: the role of the alliance learning process in alliance capability and firm-level alliance success. Strategic Management Journal, v. 28, n. 10, p. 981-1000, 2007.

KHANNA, T.; GULATI, R.; NOHRIA, N. The dynamics of learning alliances: Competition, cooperation, and relative scope. Strategic Management Journal, v. 19, n. 3, p. 193-210, 1998.

LAI, I.K.W; TAM, S.K.T.; CHAN, M.F.S. Knowledge cloud system for network collaboration: A case study in medical service industry in China. Expert Systems With Applications, v. 39, n. 15, p. $12205-12212,2012$.

LANGFIELD-SMITH, K.; SMITH, D. Management control systems and trust in outsourcing relationships. Management Accounting Research, v. 14, n. 3, p. 281-307, 2003.

LEHTONEN, T. DRG-based prospective pricing and case-mix accounting: exploring the mechanisms of successful implementation. Management Accounting Research, v. 18, n. 3, p. 367-395, 2007.

LUNNAN, R.; HAUGLAND, S.A. Predicting and measuring alliance performance: A 
multidimensional analysis. Strategic Management Journal, v. 29, n. 5, p. 545-556, 2008.

MACEDO, R.C.; MARTINS, R.S.; ROSSONI, L.; MARTINS, G.S. Confiança nos relacionamentos em cluster de empresas. RAE. Revista de Administração de Empresas, v. 57, n. 4, p. 330-341, 2017.

MADHOK, A. Reassessing the fundamentals and beyond: Ronald Coase, the transaction cost and resource-based theories of the firm and the institutional structure of production. Strategic Management Journal, v. 23, n. 6, p. 535-550, 2002.

MAHAMA, H. Management control systems, cooperation and performance in strategic supply relationships: A survey in the mines. Management Accounting Research, v. 17, n. 3, p. 315$339,2006$.

OXLEY, J.E.; SAMPSON, R.C. The scope and governance of international R\&D alliances. Strategic Management Journal, v. 25, n. 8-9, p. 723-749, 2004.

PICARD, W.; RABELO, R.J. Engagement in collaborative networks. Production Planning \& Control, v. 21, n. 2, p. 101-102, 2010.

PIZZINI, M.J. The relation between cost-system design, managers' evaluations of the relevance and usefulness of cost data, and financial performance: an empirical study of US hospitals. Accounting, Organizations and Society, v. 31, n. 2, p. 179-210, 2006.

PROVAN, K.G.; MILWARD, H.B. Do networks really work? A framework for evaluating public-sector organizational networks. Public Administration Review, v. 61, n. 4, p. 414-423, 2001.

PROVAN, K.G.; FISH, A.; SYDOW, J. Interorganizational networks at the network level: A review of the empirical literature on whole networks. Journal of Management, v. 33, n. 3, p. 479-516, 2007.

REUER, J.J.; ARIÑO, A. Strategic alliance contracts: Dimensions and determinants of contractual complexity. Strategic Management Journal, v. 28, n. 3, p. 313-330, 2007.

REUER, J.J.; KLIJN, E.; LIOUKAS, C,S. Board involvement in international joint ventures. Strategic Management Journal, v. 35, n. 11, p. 1626-1644, 2014.

SARANA, M.; MASON, R.J. The alignment of collaboration and the importance of integrated performance measurement. In: PHAM, D. T; ELDUKHRI, E. E.; SOROKA, A. J. (eds.). Intelligent Production Machines and Systems. (2nd I*PROMS Virtual International 
Conference). Oxford, UK: Elsevier, p. 45-51, 2006.

SCHIAVON, L.C.M. Gestão de relacionamento com fornecedores: Estudo de múltiplos casos em hospitais universitários. 2018. 421f. Tese (Doutorado em Engenharia de Produção) - Escola de Engenharia de São Carlos, Universidade de São Paulo, SP, 2018.

SCHLOETZER, J.D. Process integration and information sharing in supply chains. The Accounting Review, v. 87, n. 3, p. 1005-1032, 2012.

SCHREINER, M.; KALE, P.; CORSTEN, D. What really is alliance management capability and how does it impact alliance outcomes and success?. Strategic Management Journal, v. 30, n. 13, p. 1395-1419, 2009.

SOUZA, A.A.; GUERRA, M.; LARA, C.O.; GOMIDE, P.L.R.; PEREIRA, C.M.; FREITAS, D.A. Controle de gestão em organizações hospitalares. REGE. Revista de Gestão, v. 16, n. 3, p. $15,2009$.

TEO, T.S.H.; YU, Y. Online buying behavior: A transaction cost economics perspective. Omega, v. 33, n. 5, p. 451-465, 2005.

TONTINI, G.; CARVALHO, L.C.; SCHLINDWEIN, N.F.C.; TOMAREVSKI, V. Maturity model of procurement and supply management in small and medium-size enterprises: A benchmarking of hospitals and metal-mechanic companies. International Journal of Quality and Service Sciences, v. 8, n. 3, p. 315-333, 2016.

VENDEMIATTI, M.; SIQUEIRA, E.S.; FILARDI, F.; BINOTTO, E.; SIMIONI, F.J. Conflito na gestão hospitalar: O papel da liderança. Revista Ciência \& Saúde Coletiva, v. 15, n. 1, p. 1301-1314, 2010.

WALD, J.T.; LOWERY-SCHRANDTB, S.; HAYES, D.L.; KOTSENAS, A.L. Mayo clinic care network: A collaborative health care model. Journal of the American College of Radiology, v. 15, n. 1, p. 167-172, 2018.

WANG, E.T.G.; CHOU, F.K.Y.; LEE, N.C.A.; LAI, S.Z. Can intrafirm IT skills benefit interfirm integration and performance? Information \& Management, v. 51, n. 7, p. 924-938, 2014.

ZAJAC, E.J.; OLSEN, C.P. From transaction cost to transactional value analysis: Implications for the study of interorganizational strategies. Journal of Management Studies, v. 30, n. 1, p. 131-145, 1993. 


\section{APÊNDICE A - INSTRUMENTO DE PESQUISA}

\section{OBJETIVOS COLABORATIVOS}

Indique o quão importantes são os objetivos abaixo para a sua organização entrar na colaboração comprador-fornecedor. Escala: 1 = Pouco importante; 7 = Muito importante.

1. Estabilização de ganhos

2. Compartilhamento de investimentos

3. Acesso ao trabalho barato

4. Acesso a mercados locais

5. Redução da concorrência

6. Redução do risco de negócios

7. Acesso a tecnologia e/ou know-how

8. Aprender habilidades de gerenciamento

9. Acesso a outra indústria

10. Superação de barreiras (comércio/investimento)

11. Aumento da capacidade

12. Aprendizado de práticas de negócios locais

13. Acesso a redes políticas ou de negócios

\section{MENSURAÇÃO DO DESEMPENHO}

Indique o quão importantes são os critérios abaixo para avaliar o desempenho da cooperação comprador-fornecedor na sua organização. Escala: 1 = Pouco importante; 7 = Muito importante.

1. Lucro

2. Vendas

3. Fluxo de caixa

4. Custos

5. Fatia do mercado

6. Qualidade dos produtos/serviços

7. Satisfação do cliente

8. Utilização da capacidade

9. Produtividade do trabalho

10. Tempo de entrega

11. Sucesso da transferência de tecnologia

12. Número de lançamentos de novos produtos

13. Lealdade dos funcionários

14. Treinamento dos funcionários

15. Número de melhorias em produtos ou serviços

16. Introdução oportuna do produto

17. Custo por funcionário

18. Qualidade dos serviços pós-venda

19. Melhorias nos sistemas (de produção)

20. Satisfação dos funcionários

\section{CARACTERÍSTICAS DE TRANSAÇÃO}

\section{Especificidade dos ativos}

Informe em que medida os ativos abaixo são fornecidos à cooperação comprador-fornecedor pelo departamento de compras de sua organização. Escala: 1 = Muito fácil; 7 = Muito difícil.

1. Recursos financeiros

2. Localização 
3. Matérias-primas e produtos semiacabados

4. Trabalho

5. Tecnologia

6. Experiência de gestão

7. Experiência de marketing

8. Redes/relações políticas ou de negócios

9. Conhecimento do mercado local

10. Conhecimento de mercados externos

\section{Variabilidade ambiental}

Informe em que medida o ambiente da colaboração comprador-fornecedor mudou nos últimos anos em relação a cada um dos itens abaixo. Escala: 1 = Pouca mudança; 7 = Muita mudança.

11. Atividades de fornecedores (por exemplo, preço, qualidade e confiabilidade).

12. Preferências do cliente (por exemplo, preço, qualidade e confiabilidade)

13, Desenvolvimentos tecnológicos (por exemplo, tecnologia de produção)

14. Atividades de mercado dos concorrentes

15. Condições macroeconômicas gerais

16, Desenvolvimento de novos produtos ou serviços em seu setor econômico de atuação

17, Regulamentação governamental, políticas e estabelecimentos de tarifas

\section{Interdependência de tarefas}

Assinale em que medida você concorda com as afirmações que seguem, considerando o contexto da colaboração comprador-fornecedor do departamento de compras de sua organização. Escala: 1 = Discordo completamente; 7 = Concordo completamente.

18. A execução e atividades da cooperação exigem contribuições contínuas de ambos os parceiros.

19. A participação na cooperação gera conhecimento especializado e experiência para ambos os parceiros.

20. É preciso muito tempo e esforço de ambos os parceiros para compreenderem completamente as atividades dentro da cooperação. 